\title{
PERANCANGAN INSTRUMEN PENCATAT PASANG SURUT AIR LAUT SEBAGAI INDIKATOR BENCANA TSUNAMI DENGAN MENGGUNAKAN SCADA
}

\author{
Galih Mustiko Aji ${ }^{1}$, Purwiyanto \\ ${ }^{1,2}$ Jurusan Teknik Elektronika, Politeknik Negeri Cilacap \\ 1'galihma@gmail.com, ${ }^{2}$ purwi_1979@yahoo.com
}

\begin{abstract}
Abstrak
Implementasi Indonesia Tsunami Early Warning System (InaTEWS) membutuhkan anggaran yang besar. Pemerintah daerah melalui Badan Penanggulangan Bencana Daerah (BPBD) memasang perangkatperangkat pemantau pasang surut air laut (pasut laut) seperti dengan menggunakan kamera ataupun alat ukur pasut laut sederhana. Dalam rangka penguatan proses rantai peringatan dini bencana tsunami dibutuhkan implementasi teknologi yang murah namun sangat efektif. Oleh karena itu, pada artikel ini dirancang model pencatatan data pasang surut laut otomatis dengan menggunakan Palem dan Global Positioning System (GPS) yang dapat memberikan peringatan dini ketika permukaan air laut nyata berada di atas permukaan laut tertinggi High Water Spring (HWS) atau di bawah permukaan laut terendah Low Water Spring (LWS) yang diukur dalam periode waktu tertentu. Palem merupakan sensor water level yang dipasang untuk menentukan tinggi permukaan laut secara nyata, GPS digunakan untuk menentukan Benchmark (BM) dengan menunjukkan data koordinat longitude, latitude, dan altitude. Perekaman dan pengolahan data menggunakan perangkat lunak Supervisory Control And Data Acquisition (SCADA) WinTr.
\end{abstract}

Kata kunci: tsunami, pasut laut, SCADA, InaTEWS

\begin{abstract}
Implementation of Indonesian Tsunami Early Warning System (InaTEWS) requires large budgets. Local goverment through Local Disaster Relief Agency (Badan Penanggulangan Bencana Daerah, BPBD) install monitoring devices such as tidal seawatch by using camera or a simple tidal measuring devices. In order to strenghthen the process of tsunami early warning chain, implementation of technology is needed a cheap but very effective. Therefore, this article is designed model of the data recording tidal sea automatically by using palm and Global Positioning System (GPS) that can provide early warning when the sea level is above the highest (HWS) or below the lowest (LWS) sea level as measured in a given time period. Palm is a water level sensor mounted to determined sea levels significantly and GPS is used to determine the Bench Mark (BM) by showing the coordinate data longitude, latitude, and altitude. Data recording and processing using Supervisory Control and Data Acquisition (SCADA) WinTr Software.
\end{abstract}

Keywords: tsunami, sea tide, SCADA, InaTEWS

\section{Pendahuluan}

Gangguan impulsif pada dasar laut yang terjadi karena perubahan bentuk struktur geologis dasar laut secara vertikal dan dalam waktu singkat menyebabkan gelombang air laut yang merambat ke segala arah. Fenomena ini biasanya disebut sebagai tsunami [1]. Penyebab utama tsunami di Indonesia adalah gempa bumi tektonik [2]. Hampir seluruh wilayah pantai di Indonesia yang berhadapan langsung dengan Samudra Hindia berpotensi terhadap tsunami [3]. Implementasi Indonesia Tsunami Early Warning System (InaTEWS) tentu saja membutuhkan anggaran yang besar, belum lagi pada perawatan perangkat dan resiko-resiko yang akan terjadi. Badan Meteorologi, Klimatologi, dan Geofisika(BMKG) menerbitkan informasi berita peringatan dini tsunami dalam kurun waktu 5 menit setelah terjadi gempa bumi [4]. Berita informasi peringatan dini tsunami akan terus diperbarui sampai berita ancaman telah berakhir. Berita informasi peringatan dini harus mampu diterima secara tepat dan sepanjang waktu oleh pemerintah daerah melalui berbagai macam alat komunikasi. Pemerintah daerah harus mampu mengambil keputusan tentang tindakan yang diperlukan yaitu perlu atau tidak melakukan evakuasi secara cepat dan tepat berdasarkan informasi yang diterima oleh BMKG [4]. Untuk membantu pengambilan keputusan tentang tindakan yang diperlukan ketika mendapat informasi bencana tsunami, pemerintah Kabupaten Cilacap melalui Badan Penanggulangan Bencana Daerah (BPBD) memasang kamera pemantau di Pantai Teluk Penyu [5]. Pemasangan 
kamera ini berguna untuk memantau dan mengetahui dengan cepat tanda-tanda tsunami melalui pasang - surut air laut. BPBD Kabupaten Pacitan memasang dan mengadakan sistem pemantauan pasang surut dengan teknologi sederhana yang juga digunakan untuk memantau tanda-tanda tsunami.

Pada penelitian ini dibahas tentang instrumen pencatat pasang surut air laut otomatis dengan menggunakan model pengamat Palem yang disusun dari sensor water level untuk mengetahui permukaan air laut secara nyata dan Global Positioning System (GPS) yang digunakan sebagai Bench Mark (BM). Instrumen pencatat pasang surut air laut akan menghitung permukaan air laut tertinggi (HWS) dan permukaan air laut terendah (LWS) dalam kurun waktu tertentu sebagai acuan peringatan apabila permukaan air laut nyata melebihi nilai HWS atau kurang dari nilai LWS. Pengolahan data dan perekaman data dilakukan oleh perangkat lunak Supervisory Control And Data Acquisition (SCADA) WinTr.

Luaran yang diharapkan dari perancangan instrumen pencatat pasang surut air laut otomatis dengan menggunakan SCADA WinTr adalah untuk membantu Badan Penanggulangan Bencana Daerah (BPBD) dalam upaya penguatan rantai peringatan dini bencana tsunami.

\section{Tinjauan Pustaka}

\subsection{Pengamatan Pasang Surut Air Laut}

Pasang surut air laut merupakan fenomena naik turunnya permukaan air laut secara periodik sebagai akibat gaya tarik menarik antara bumi, bulan, dan matahari [6]. Pengamatan pasang surut laut secara prinsip adalah mengamati perubahan kedudukan permukaan laut dalam selang waktu tertentu. Alat pengamat pasang surut sederhana dapat menggunakan model Palem yaitu kayu dengan ukuran panjang sekitar 3 - 5 meter, lebar $5-15 \mathrm{~cm}$ sedangkan tebalnya $1-4 \mathrm{~cm}$. Alat ukur ini mirip seperti rambu ukur dimana mempunyai skala bacaan dalam satuan desimeter. Agar ukuran pengamatan air laut benar, maka pemasangan Palem harus tegak lurus dengan permukaan air laut. Cara pelaksanaan yang paling sederhana untuk mengamati pasang surut laut yaitu dengan cara menempatkan rambu ukur atau Palem pada tempat yang memungkinkan seperti yang diilustrasikan pada Gambar 1 .

Pada saat pengamatan pasang surut dengan menggunakan Palem perlu dilakukan suatu prosedur untuk mengetahui kedudukan nol Palem relatif terhadap suatu titik di pantai (Benchmark). Kedudukan nol dapat dilakukan dengan menggunakan pengukuran GPS di pantai.

Pelaksanaan pengukuran GPS dilakukan dengan membuat terlebih dahulu tugu survei, tugu survei digunakan sebagai representasi dari koordinat acuan Bench Mark (BM) [7]. Receiver GPS dipasang tepat di atas BM yaitu unting-unting receiver terletak lurus di atas titik tengah BM. Agar pengukuran dapat dilakukan dengan baik dan menghasilkan posisi yang minim kesalahan, syaratsyarat pengukuran harus dipenuhi diantaranya lokasi pengukuran mempunyai ruang pandang yang terbuka ke langit untuk memudahkan sinyal GPS mencapai antena receiver, jauh dari objek atau benda yang mudah memantulkan sinyal GPS.

Pengamatan GPS pada stasiun pasang surut air laut akan menghasilkan posisi tiga dimensi dengan sistem koordinat geodetik [7]. Koordinat geodetik bisa dalam koordinat kartesian maupun koordinat geodetik. Dalam pelaksanaan survei GPS di BM dihasilkan ketinggian Geoid. Means Sea Level (MSL) adalah tinggi laut terhadap BM di darat, dirata-rata terhadap suatu periode waktu tertentu yang cukup panjang, sebulan atau setahun, sehingga fluktuasi akibat gelombang dan pasang surut sebisa mungkin dihilangkan. Setelah MSL diketahui dari proses pengolahan data maka tinggi orthometrik BM akan diketahui. Gambar 2 menunjukkan hubungan antara pengukuran GPS pada BM dan pengukuran pasut [7].

Geoid adalah bidang ekipotensial gaya berat bumi yang menyinggung muka laut. Geoid sering dinyatakan sebagai bentuk bumi yang sebenarnya. Bentuk Geoid tidak beraturan dan hanya bisa ditentukan melalui pengamatan medan gaya berat. Karena merupakan ekipotensial, gaya berat setiap titik pada Geoid selalu tegak lurus dengan medan gaya berat.

Geoid digunakan sebagai referensi tinggi untuk levelling. Untuk keperluan praktis, pengukuran ketinggian menunjukkan pada MSL yang mendekati Geoid. Tinggi dari permukaan Geoid disebut tinggi ortometric. Sedangkan tinggi Elipsoid (h) dapat dihitung dengan persamaan (1) berikut [1]:

$$
h=H+N
$$

dimana,

$\mathrm{h}=$ ketingian elipsoid

$\mathrm{H}=$ ketinggian orthometric (MSL)

$\mathrm{N}=$ ketinggian Geoid

\subsection{Supervisory Control And Data Acquisition (SCADA)}

SCADA merupakan sebuah sistem yang mengumpulkan informasi atau data-data dari lapangan dan kemudian mengirimkan nya ke sebuah komputer pusat yang akan mengatur dan mengontrol data-data tersebut [8]. Sistem SCADA melakukan pemantauan data-data dari berbagai macam sensor di lapangan atau bahkan dari tempat-tempat yang lebih jauh (remote locations). Sistem pemantauan dan kontrol SCADA terdiri dari sebuah host pusat atau master (MTU), satu atau lebih unit-unit pengumpul 
dan kontrol data lapangan atau remote station (RTU) dan perangkat lunak yang digunakan untuk memantau dan mengontrol elemen-elemen data di lapangan. Arsitektur SCADA diperlihatkan pada Gambar 3.

Sistem SCADA memiliki fungsi yaitu untuk pengukuran jarak jauh (telemetering) dan pengendalian jarak jauh (telecontrolling).

\subsection{Protokol Modbus}

Protokol modbus merupakan aturan-aturan komunikasi data dengan teknik Master - Slave [8]. Dalam komunikasi tersebut hanya terdapat satu Master dan satu atau beberapa Slave yang membentuk sebuah jaringan. Komunikasi Modbus selalu diawali dengan query dari Master, dan Slave memberikan respons dengan mengirimkan data atau melakukan aksi sesuai perintah dari Master. Master hanya melakukan satu komunikasi dalam satu waktu. Slave hanya akan melakukan komunikasi jika ada perintah (query) dari Master dan tidak bisa melakukan komunikasi dengan Slave yang lain.

Pada saat mengirimkan query ke Slave, Master menggunakan 2 mode pengalamatan, yaitu:

\section{- $\quad$ Unicast mode}

Master mengirimkan query kepada satu slave. Setelah menerima dan memproses query, Slave akan memberikan jawaban berupa respon kepada Master.

\section{- Broadcast mode}

Master mengirimkan perintah (query) kepada semua Slave. Pada mode pengalamatan ini Slave tidak mengirimkan respon kepada Master.

Protokol modbus membentuk sebuah format pesan untuk query Master dan respons Slave. Adapun siklus pengiriman query - respon ditunjukkan pada Gambar 4.

Dalam jaringan modbus terdapat 2 mode transmisi serial, yaitu mode RTU dan mode ASCII. Pada mode RTU, frame pesan dipisahkan oleh silent interval paling sedikit waktu 3,5 karakter. Masingmasing Slave harus mempunyai alamat yang berbeda dalam range 1 - 247 untuk pengalamatan individual. Alamat 0 digunakan untuk pengalamatan broadcast. Function code berfungsi untuk memberitahu Slave tentang perintah yang harus dikerjakan dan sebagai indikasi respon normal atau jenis error yang terjadi (exception response). Data field pada query berisi kode sebagai informasi tambahan pada function code tentang aksi yang harus dikerjakan Slave. Informasi tersebut dapat berupa alamat input - output, jumlah input - output, jumlah byte data, atau nilai data pengesetan. Sedangkan Error Check pada mode RTU menggunnakan CRC (Cyclical Redundancy
Check) yaitu error checking field yang berisi sebuah nilai 16 bit ( 2 byte).

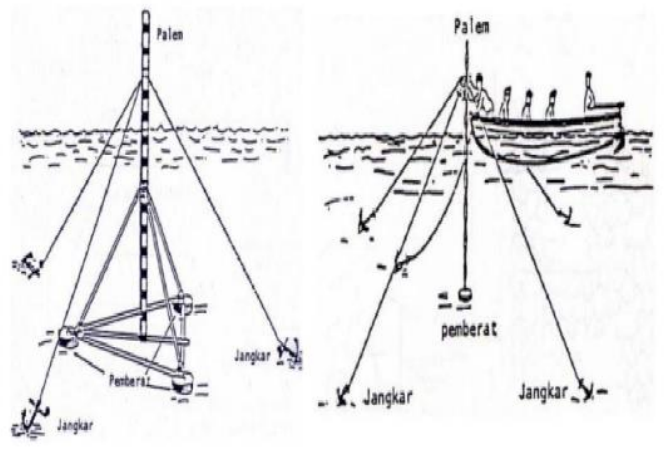

Gambar 1. Alat Pengamat Pasang Surut Laut Palem

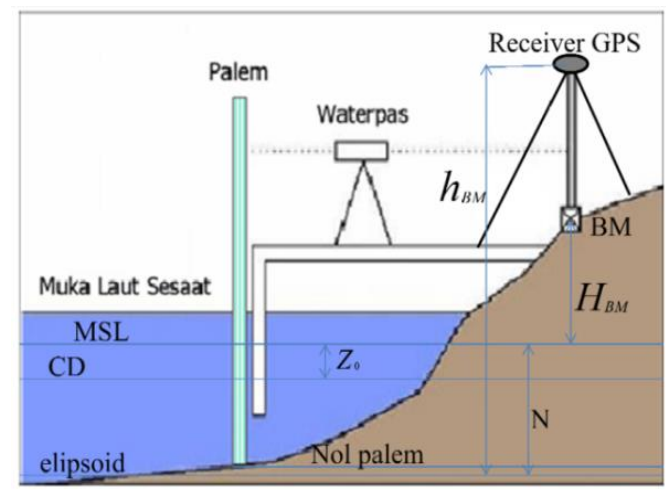

Gambar 2. Hubungan Matematis Pengukuran GPS pada BM dan Pengukuran Pasut

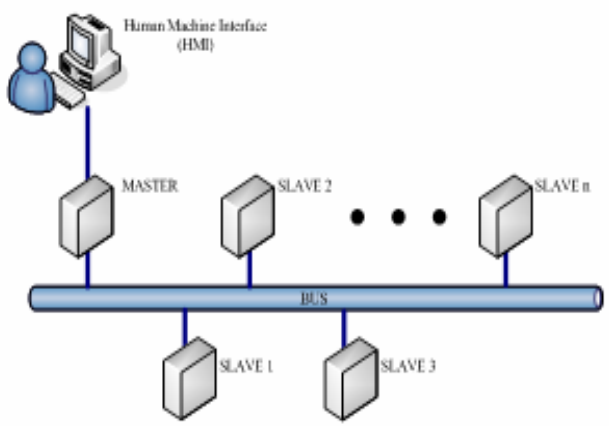

Gambar 3. Arsitektur SCADA [8]

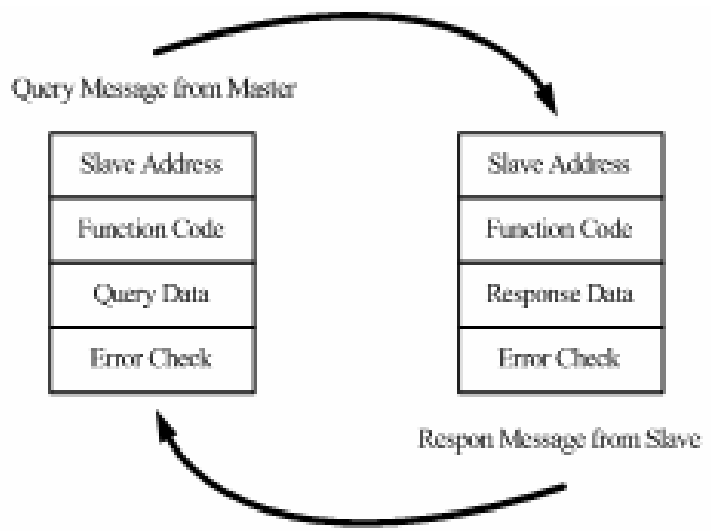

Gambar 4. Siklus Pengiriman Query - Respon 


\section{Perancangan Sistem}

Perancangan instrumen pencatat pasang surut air laut otomatis dengan menggunakan SCADA dari tiap-tiap bagian dapat ditunjukkan dalam blok diagram pada Gambar 5.

Sistem SCADA difungsikan sebagai telemetering yaitu pengukuran Palem dan modul GPS jarak jauh. Arduino Uno digunakan sebagai antarmuka perangkat ke PC dan untuk menangani protokol modbus. Node sensor berupa Palem dan GPS yang diolah terlebih dahulu oleh ATmega8535 sebelum ditransmisikan ke SCADA.

\subsection{Perancangan Palem}

Palem adalah node sensor yang diletakan di laut lepas yang memberikan data nilai permukaan air laut. Model Palem yang digunakan menggunakan sensor water level yang dipasang pada tiang dengan jarak antar sensor adalah $20 \mathrm{~cm}$ dengan panjang 3 meter (sesuai dengan interval HWS ke LWS). Model Palem yang dirancang ditunjukkan pada Gambar 6.

Penggunaan material berbahan plastik diharapkan dapat menjadi solusi untuk mengurangi resiko korosif. Palem kemudian dimasukkan ke dalam pipa besar yang di beri lubang-lubang kecil sebagai penyaring air agar tidak terganggu oleh sampah dan benda-benda laut lain. Sensor water level dihubungkan melalui antarmuka digital pada mikrokontroler dengan logika boolean.

\subsection{Perancangan Modul GPS}

Modul GPS digunakan untuk menampilkan hasil pembacaan ketinggian MSL (Mean Sea Level), ketinggian geoid dan data latitude serta longitude. Ketinggian MSL atau muka laut rata-rata adalah rata-rata nilai tinggi muka laut selama pengamatan. Nilai tinggi muka air laut pada setiap titik pengukuran selama pengamatan dihitung untuk mencari nilai rata-rata pengukurannya. Pada perekaman data satelit, jarak antar rekaman lebih kurang $5 \mathrm{~km}$, sedangkan untuk rekaman pada titik yang seharusnya sama, terdapat perbedaan jarak kurang lebih $1 \mathrm{~km}$ per cycle [7].

Modul GPS memberikan data ketinggian geoid yang berasal dari pengukuran tiga dimensi GPS, yaitu ketinggian geodetiknya. GPS yang digunakan dalam instrumen ini adalah modul neo GPS starter kit seperti yang ditunjukkan oleh Gambar 7.

Antarmuka modul GPS melalui komunikasi serial UART yang mampu memberikan data permukaan laut rata-rata (MSL), ketinggian geoid, latitude, dan longitude seperti yang ditunjukkan pada LCD karakter pada Gambar 8. Data yang ditampilkan pada LCD karakter adalah data yang didapatkan dari pengukuran modul GPS. Data MSL dan Geoid ditransmisikan oleh ATmega8535 ke
SCADA sedangkan data longitude dan latitude digunakan sebagai penunjuk lokasi pengukuran.

\subsection{Perancangan SCADA}

Perangkat lunak menggunakan SCADA WinTr. Arduino Uno digunakan sebagai Slave pada modbus RTU dengan baudrate 9600 bps, 8, n, 1. Arduino Uno menerima masukan data dari ATmega8535 yang mengolah data GPS dan sensor. Skematik rangkaian Slave modbus RTU untuk berkomunikasi dengan perangkat lunak SCADA ditunjukkan pada Gambar 9. Slave modbus RTU menyimpan data analog 16 - bit pada holding register dengan susunan sesuai pada Tabel 1.

Data dari perangkat Palem dan GPS dikirimkan oleh mikrokontroler ke komputer untuk dilakukan pengolahan lanjut dan perekaman data. Pengolahan dan perekaman data dilakukan oleh perangkat lunak SCADA WinTr dalam bentuk grafik dan dapat dicetak dalam tabel seperti yang ditunjukkan oleh Gambar 10.

Grafik di sebelah kiri menunjukkan perekaman data Palem dan grafik sebelah kanan menunjukkan perekaman muka laut rata-rata dan geoid yang dilakukan oleh GPS. Selama perekaman data real time, akan memberikan peringatan apabila data melebihi atau kurang dari angka wajar. Peringatan ini merupakan indikator awal adanya bencana tsunami yaitu pasang - surutnya air laut yang melewati angka wajar.

Tabel 1. Pengalamatan data modbus RTU

\begin{tabular}{lll}
\hline Data & Alamat & Keterangan \\
\hline Palem & 40001 & Holding Register \\
MSL & 40002 & Holding Register \\
Geoid & 40003 & Holding Register \\
\hline
\end{tabular}

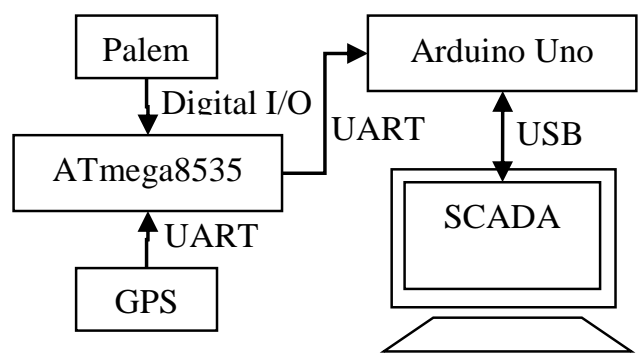

Gambar 5. Blok diagram sistem instrumen pencatat pasang surut air laut

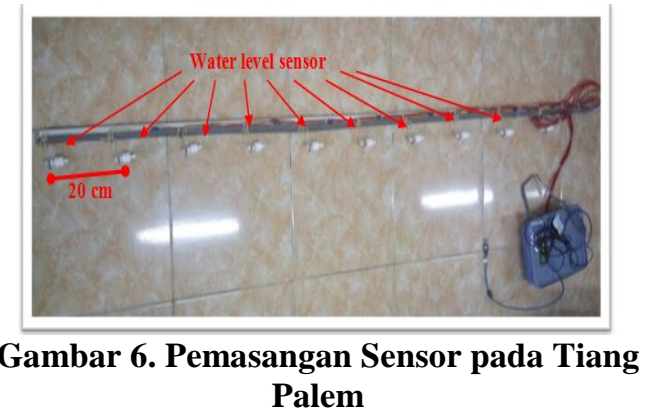




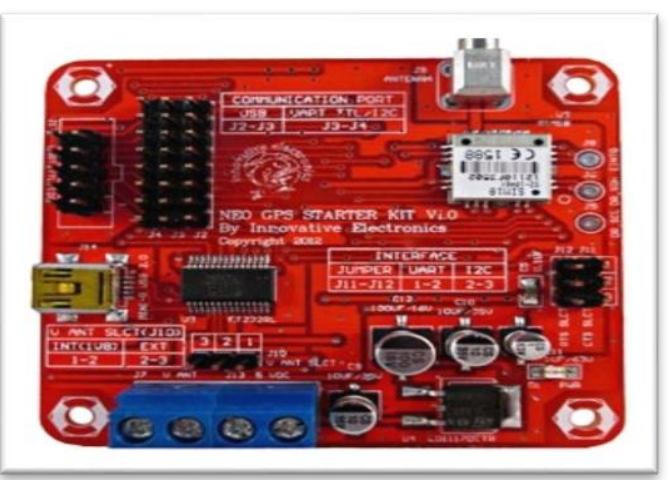

Gambar 7. Modul Neo GPS Starter Kit

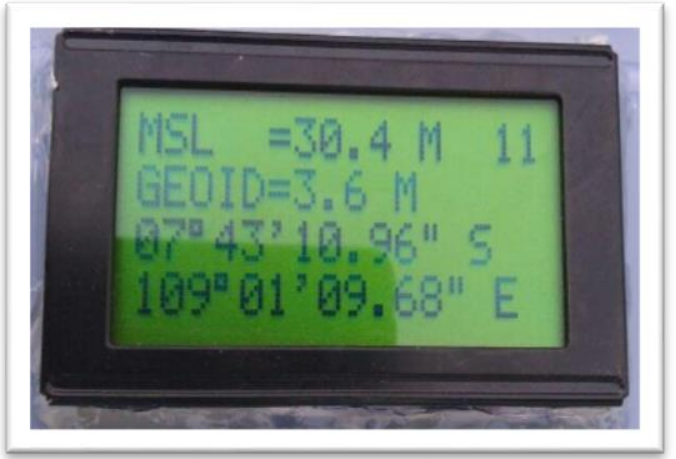

Gambar 8. Hasil Pembacaan Data Modul GPS

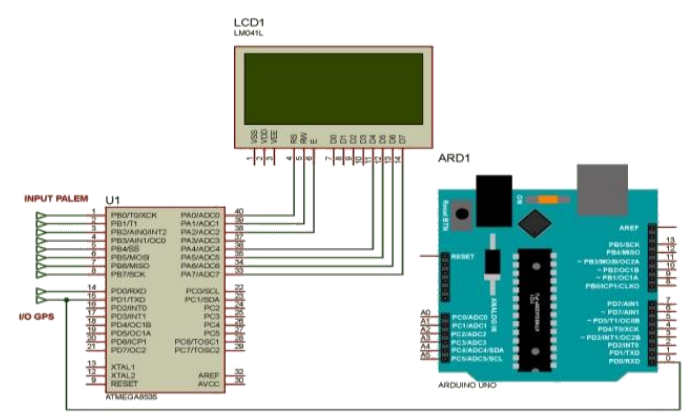

Gambar 9. Skematik Rangkaian Slave Modbus RTU

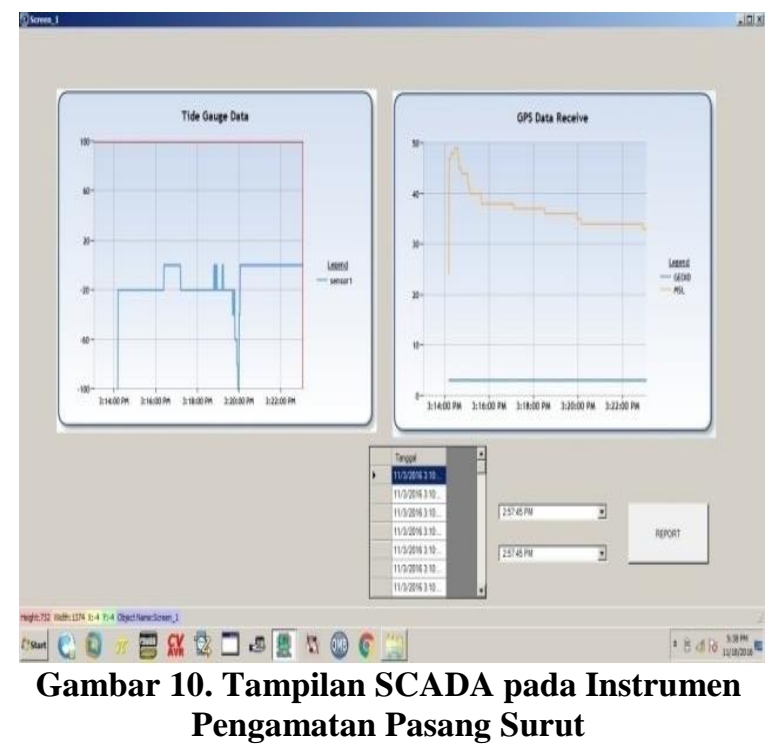

\section{Pengujian Sistem}

Pengujian dilakukan dengan mengamati karakteristik MSL untuk mendapatkan nilai HWS dan LWS, ketinggian geoid dan karakteristik Palem sebagai parameter pada pemasangan instrumen.

Pengujian menunjukkan ketinggian geoid ditempat tersebut adalah 3 meter, sedangkan untuk ketinggian MSL dalam kurun waktu kurang dari 24 jam didapatkan rata-rata adalah 17,5 meter dengan HWS 21 meter dan LWS 10 meter. Dengan menggunakan persamaan (1) maka dapat dihitung ketinggian elipsoid (h) adalah 20,5 meter.

Dengan data tersebut maka dapat diambil kesimpulan bahwa Palem yang dibutuhkan adalah sepanjang 11 meter. Palem dipasang pada posisi HWS dan LWS, ketika level air di luar angka HWS dan LWS maka sebuah indikator pada SCADA WinTr akan diberikan sebagai penanda bahaya tsunami. Dalam penelitian ini, Palem yang dibuat sepanjang 3 meter.

\section{Kesimpulan}

Dari hasil pengujian dan analisa pada instrumen pencacat data pasut air laut dengan GPS dan Palem dapat diambil kesimpulan sebagai berikut:

1) Penggunaan GPS untuk menentukan Benchmark (BM) mampu memberikan data posisi Geoid, MSL, HWS dan LWS.

2) Palem membaca permukaan air laut secara nyata dan memberikan peringatan berupa indikator bencana tsunami ketika level air melebihi HWS dan kurang dari LWS.

3) Penggunaan SCADA WinTr memberikan kemudahan dalam pengamatan dan perekeman data muka laut air laut.

\section{Daftar Pustaka}

[1] M. Ramdhan, "Komparasi Hasil Pengamatan Pasang Surut di Perairan Pulau Pramuka dan Kabupaten Pati dengan Prediksi Pasang Surut Tide Model Driver," Segera, vol. 7, no. 1, pp. 112, 2011.

[2] Purwa and Q. , "Simulasi Pembangkitan dan Penjalaran Gelombang Tsunami Berdasarkan Skenario Gempa Tektonik," Teknik POMITS, vol. 1, no. 1, pp. 1-6, 2014.

[3] Purwanto and H. Sigit, "Mewaspadai Morfologi Teluk Sebagai Zona Bahaya Tsunami," MTG, vol. 1, no. 1, 2008.

[4] Pusat Gempa Bumi dan Tsunami, "Pedoman Pelayanan Peringatan Dini Tsunami," Jakarta, BMKG, 2012.

[5] Wagino, "BPBD Pasang Kamera Pantau Pasang Surut Air Laut," [Online]. Available: http://cilacapmedia.com/index.php/seputar- 
cilacap/2789-bpbd-pasang-kamera-pantaupasang-surut-air-laut.html . [Accessed 2 Maret 2016].

[6] Efwilza and Dedi, Studi Penerapan Komunikasi Tide Gauge Pada Sistem Peringatan Dini Tsunami di Padang, Bandung: Fakultas Ilmu Terapan, Universitas Telkom, 2007.

[7] Fansuri and M. Hamsad, Pemantauan Data GPS Kontinyu Menuju Survei Batimetrik Real Time, Bandung: Department of Geodetic Engineering, ITB, 2008.

[8] Tiyono and A. , Sistem Telekonrol SCADA dengan Fungsi Dasar Modbus Menggunakan Mikrokontroler AT8951 dan Komunikasi Serial RS485, Semarang: Jurusan Teknik Elektro, Universitas Diponegoro, 2007. 